\title{
Aggressive Behavior in Young Children Co-detained with Imprisoned Mothers
}

\author{
Shilpi Sarkar ${ }^{1}$ (D) Sandhya Gupta ${ }^{2}$
}

Received: 13 June 2017 / Accepted: 20 September 2017

(C) Dr. K C Chaudhuri Foundation 2017

To the Editor: A home is comprised by family members and is the safety umbrella of elements of basic needs essential for child growth and development. Unlike home, in prison, children are inevitably exposed to aggressive environmental influence due to the behavior of mother and other imprisoned women. Aggression is defined as any behavior intended to harm another person who does not want to be harmed. Persistent aggression in childhood is related to a variety of negative outcomes in adulthood [1]. Childhood exposure to violence is associated with a variety of aggressive and maladaptive behaviors [2]. Children are most vulnerable to be influenced by aggressive environment than adults as adults already develop their own sets of morals and values and seeing aggression does not affect them so much [3]. Justice system of India permits codetention of children (upto $6 \mathrm{y}$ ) with imprisoned mothers in prison. The present article identifies the aggressive behavior in children co-detained with imprisoned mothers.

A cross-sectional study was conducted at the Central prison of Delhi. Prison staff members of the crèche were interviewed to rate co-detained child's ( 3 to $5 \mathrm{y}$ ) behavior for aggression. Out of sixteen children, aggressive behavior was observed in 13 (81\%, 95\% C.I: 57\%-93\%) co-detained children, in moderate $5(31 \%, 95 \%$ C.I: $14 \%-55 \%)$ or severe $8(50 \%, 95 \%$ C.I: $28 \%-72 \%)$ grades.

Sandhya Gupta

Drsandhyag407@gmail.com

Shilpi Sarkar

shilpisarkaraiims@gmail.com

1 Faculty of Nursing, Jamia Hamdard, Delhi, India

2 Department of Mental Health Nursing, College of Nursing, All India Institute of Medical Sciences, Ansari Nagar, Delhi 110029, India
In the prison, more than three-fourth of co-detained children were found to have moderate to severe grades of aggressive behavior. Imprisoned mother might exercise aggressive parenting as overcrowding is reported to make parenting more punitive [4]. When imprisoned mothers try to solve problems with physical or verbal violence, children mistakenly learn that as an appropriate behavior and behave aggressively [5].

Strict prison policy is required against the use of abusive language and prevention of frequent fights among prisoners. Parenting classes needs to be organized for imprisoned mothers and training of the crèche teachers to manage aggressive behavior of children in the early stages.

\section{Compliance with Ethical Standards}

Conflict of Interest None.

Source of Funding None.

\section{References}

1. Buchmann A, Hohmann S, Brandeis D, Banaschewski T, Poustka L. Aggression in children and adolescents. Curr Top Behav Neurosci. 2014;17:421-42.

2. Osofsky JD, Osofsk HJ. Children's exposure to violence - community violence, domestic violence - general effects. Envision summer programs Available at: http://education.stateuniversity.com/pages/ 2531/Violence-Children-s-Exposure.html. Accessed 21 Feb 2017.

3. Berkowitz L. On the formation and regulation of anger and aggression: a cognitive neoassociationistic analysis. Am Psychol. 1990;45:494-503.

4. Evans GW, Ricciuti HN, Hope S, et al. Crowding and cognitive development. The mediating role of maternal responsiveness among 36-month-old children. Environ Behav. 2010;42:135-48.

5. Mitrofan O, Paul M, Weich S, Spencer N. Aggression in children with behavioural/emotional difficulties: seeing aggression on television and video games. BMC Psychiatry. 2014;14:287. 